\title{
Age-related Bruch's membrane change: a clinical study of the relative role of heredity and environment
}

Bertrand Piguet, John A Wells, Inge B Palmvang, Richard Wormald, Iain H Chisholm, Alan C Bird

\begin{abstract}
For many years there has been controversy concerning the role of genetic influences in the pathogenesis of age-related macular disease. It is widely believed that the lesions causing visual loss occur in response to age-related changes in Bruch's membrane which are recognised clinically as drusen. In this study the density, size, and confluence of drusen as shown on colour photographs were compared in eyes of 50 spouses and 53 sibling pairs ascertained during a prospective study of agerelated macular disease. Concordance between pairs of drusen - number, size, and density - were determined by $x$ statistic and $\chi^{2}$ test for trend. Drusen were absent in one sibling and 26 spouses of patients. There was a trend towards concordance of drusen characteristics between siblings but not between spouses, although the difference achieved $5 \%$ significance only for the number and density of drusen in the central macula. The difference of concordance between the probands and spouses and the probands and siblings was significant for all characteristics. These findings support the belief that genetic factors influence age-related changes in Bruch's membrane. They also imply that environmental factors are less important or alternatively that the environmental variation between households included in our study was not great enough to be evident.

(Br f Ophthalmol 1993; 77: 400-403)
\end{abstract}

Age-related maculopathy (ARM) is now considered the most common cause of registered blindness in Western countries. ${ }^{1-4}$ The lesions that cause loss of central vision are growth of new vessels within Bruch's membrane, detachment of the retinal pigment epithelium (RPE), and geographic atrophy. ${ }^{5}$ These are widely believed to occur in response to age-related changes at the level of Bruch's membrane which are thought to result from the accumulation of material released from the pigment epithelial cells into Bruch's membrane. ${ }^{-10}$ These changes are recognised clinically as drusen. ${ }^{11-16}$

For years drusen occurring as a consequence of age have been considered distinct from those which are inherited in an autosomal dominant fashion. Several reports of familial drusen have been published since the first description by
Doyne in $1899,{ }^{17}$ and terms have been used to describe these such as Doyne's honeycomb choroiditis, Tay's central guttate choroiditis, Holthouse-Batten's superficial choroiditis, and Malattia levantinese. ${ }^{17-20}$ The conditions were considered to be due to one or several dominant gene mutations. ${ }^{21-24}$

More recently it has been suggested that familial drusen and drusen consequent upon age both correspond to the same heredodegenerative disease. ${ }^{23-25}$ In 1973 Gass $^{25}$ found a positive family history of ARM in $20 \%$ of 200 patients with drusen or disciform lesions, although this was confirmed in only $5 \%$. In a case control study of patients with drusen, Hyman $e t a l^{26}$ assessed the effects of several host and environmental factors on this condition. They showed a statistically significant association between ARM and maternal or sibling history of macular disease, and concluded that the development of ARM was mainly influenced by familial, genetic, and personal characteristics rather than by the studied environmental factors. However, it was pointed out that the findings had to be interpreted with caution, as the family history of ARM was ascertained by interview alone, and it was impossible to validate this in an elderly population. In a smaller study, Delaney ${ }^{27}$ failed to confirm this observation, and recognised the extreme difficulty in placing much trust in historical evidence of an eye disease which was not apparent until after the age of 60 years.

Regarding the role of environment, $\mathrm{Hyman}^{26}$ suggested that history of chronic chemical exposure, including cigarette tobacco, could increase the risk of development of ARM in men but not in women. This was at a borderline level of statistical significance, and the association between ARM and cigarette smoking has not been confirmed in other studies. ${ }^{28} 29$

Despite the wide belief that there may be a genetic influence on the genesis of drusen, there is currently no study to confirm this. To date all epidemiological and clinical studies have been based on family history alone. ${ }^{26} 27$

The risk to vision in age-related disease depends upon the quantity and form of drusen, and the reaction that they evoke. By examining the concordance of morphological characteristics of drusen between pairs of siblings our study was designed to gain more information on the potential role of heredity in the genesis of the changes predisposing to visual loss. By seeking concord- 
ance between changes observed in probands and their spouses it was also hoped to provide further evidence regarding the role of environmental factors in the genesis of the disease. This prospective study was designed only to assess the possible association of age-related changes in Bruch's membrane with genetic and/or environmental factors but was not conceived to identify what type of factors, if present, could be important to the development of the disorder.

\section{Patients and methods}

Patients recruited to a prospective longitudinal study of age-related macular disease were asked if they had a sibling or spouse who would be willing to take part in a study of their eyes. From 82 patients it was possible to obtain 53 spouses and 50 sibling pairs who were eligible for the study, and who agreed to have their fundus examined and to undergo fundus photography. All gave signed consent to the study which was approved by the ethical committee of Moorfields eye hospital.

Only spouses who had shared more than 20 years of common life with the patient were eligible for the study. No more than one sibling of each patient was included, and when two of them attended the clinic the one whose age was the closest to the patient's was selected. In each case the difference of age between the two members of the pair (patient spouse or patient sibling) was 10 years or less.

The exclusion criteria included the following: (1) presence of any other ocular disease (for example, cataract) sufficient to preclude fundus examination or good quality photographs, (2) macular degeneration related to myopia, and (3) the presence of other macular disease.

All the patients were aged 57 years or more. They had either bilateral drusen with good vision, or unilateral drusen and contralateral visual loss as a result of pigment epithelial detachment, choroidal neovascularisation, or disciform scar.

When one eye only was available for assessment because of a lesion related to ARM in the other, that same eye was examined in the spouse or the sibling. In cases of bilateral drusen, the right eye was selected.

Colour photographs were analysed independently by two of us (JW and BP). The macula was divided in a central area within $1600 \mu \mathrm{m}$ of the foveola and a peripheral area between 1600 and $2800 \mu \mathrm{m}$ of the foveola, and the drusen were analysed according to number, size, and density of drusen for each region, using a previously reported grading system which has been shown to be reproducible. ${ }^{30-33}$ They were categorised according to whether there were or were not drusen. If present the number was classified as $<10$ drusen, 10-20 drusen, or $>20$ drusen in

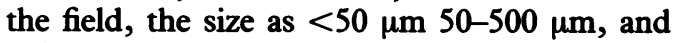
$>500 \mu \mathrm{m}$, and the density as scattered if drusen were distinct one from another, subconfluent if their borders were just touching and confluent if the borders overlapped. In the majority of the cases the drusen were uniform in size, and density. When this was not the case, the classification was determined according to the charac-
Table 1 Sex and age in sibling and spouse pairs

\begin{tabular}{|c|c|c|c|c|}
\hline & \multicolumn{2}{|c|}{ Sibling pairs } & \multicolumn{2}{|c|}{ Spouse pairs } \\
\hline & Proband & Sibling & Proband & Spouse \\
\hline $\begin{array}{l}\text { Men (\%) } \\
\text { Women (\%) } \\
\text { Mean age (years) } \\
\text { Range in age (years) }\end{array}$ & $\begin{array}{l}22(44) \\
28(56) \\
68 \\
57-84\end{array}$ & $\begin{array}{l}21(42) \\
29(58) \\
65 \\
59-82\end{array}$ & $\begin{array}{l}20(38) \\
33(62) \\
65 \\
59-84\end{array}$ & $\begin{array}{l}33(62) \\
20(38) \\
62 \\
60-83\end{array}$ \\
\hline
\end{tabular}

Table 2 Weighted $x$ values in siblings and spouse

\begin{tabular}{|c|c|c|c|c|c|c|c|c|}
\hline & \multicolumn{4}{|c|}{ Sibling pairs } & \multicolumn{4}{|c|}{ Spouse pairs } \\
\hline & \multicolumn{2}{|c|}{ Central } & \multicolumn{2}{|c|}{ Peripheral } & \multicolumn{2}{|l|}{ Central } & \multicolumn{2}{|c|}{ Peripheral } \\
\hline & $x$ & $S E$ & $x$ & $S E$ & $x$ & $S E$ & $x$ & $S E$ \\
\hline $\begin{array}{l}\text { Number } \\
\text { Density } \\
\text { Size }\end{array}$ & $\begin{array}{l}0.33 \\
0.29 \\
0.08\end{array}$ & $\begin{array}{l}0 \cdot 10 \\
0 \cdot 11 \\
0 \cdot 12\end{array}$ & $\begin{array}{l}0.20 \\
0.21 \\
0.06\end{array}$ & $\begin{array}{l}0 \cdot 11 \\
0 \cdot 12 \\
0 \cdot 38\end{array}$ & $\begin{array}{r}-0.05 \\
0.02 \\
-0.07\end{array}$ & $\begin{array}{l}0.04 \\
0.05 \\
0.04\end{array}$ & $\begin{array}{l}0.01 \\
0.06 \\
0.03\end{array}$ & $\begin{array}{l}0.04 \\
0.05 \\
0.04\end{array}$ \\
\hline
\end{tabular}

$\mathrm{SE}=$ standard error. The weighted $x$ is calculated using the formula

$\mathrm{W}_{i j}=1-\frac{(i-j)^{2}}{(k-1)^{2}}$

where $i$ and $j$ are the different values for each cell and $k$ is the number of categories. ${ }^{34}$

teristics of the majority of the drusen. In case of disagreement between the two readers, the results were assigned only after a third observer was asked to arbitrate. The characteristic was designated as ' 0 ' if there were no drusen, and ' 1 ', ' 2 ', or ' 3 ' as the drusen became more numerous, more densely packed, and larger.

The results of the drusen analysis were recorded and subjected to statistical analysis. Weighted $x$ statistic was used to assess the concordance between the pairs of spouses or siblings in which different weights are given to the measure of concordance on a relative scale. These statistics evaluate the observed concordance beyond chance, related to the maximum possible agreement in excess of chance alone.$^{34} \mathrm{In}$ most situations, a $x$ value of 0.75 or more indicates an excellent concordance, a value of 0.4 to 0.75 a good concordance; between 0.4 to 0 a low level of concordance but that which is greater than would be expected by chance alone, and 0 absence of concordance. It is recognised that asymmetry is introduced by selecting the proband for the presence of drusen such that some cells contain zero counts.

In addition the numerical difference in classification between each sibling and spouse pair was recorded, and the two groups compared using $\chi^{2}$ and $\chi^{2}$ for trend.

\section{Results}

The two groups were similar in terms of age and sex, although there was a slight preponderance of female probands and male spouses in the spouse group (Table 1). The average age was 68 years (range 57 to 84 years) for the patients and 65 years (range 59 to 82 years) for the siblings. Of the 106 in the spouse group, the average age was 65 years (range 59-84) for the patients and 62 years (range 60-83) for the spouse.

Only one sibling was free of drusen in the central macula and nine had no drusen in the peripheral macula; the figures for the spouses were 26 and 35. This difference between the 
sibling and spouse groups was highly significant ( $p$ value $<0.001$ ) for the central and the peripheral macula (Fisher's exact test).

Despite the presence of clustering, there was concordance which was greater than would have been expected by chance alone between siblings regarding the size, density, and number of drusen (Table 2, Fig 1). Such degree of concordance was not found between spouses (Table 2 , Fig 1).

Using $95 \%$ confidence limits for each $x$ estimate, the concordance was statistically significantly higher between siblings than between spouses for the number and density of drusen in the central macula only, and the standard errors were consistently higher in sibling pairs (Table 2, Fig 1). This level of statistical difference was not reached between the two groups regarding the size of drusen in the central macula or the size, number, and density of drusen in the peripheral macula, despite a higher weighted $x$ value in the siblings group for all the drusen characteristics.

$x$ Values for siblings of the same sex ( 20 female and 10 male pairs) were not different from those in the sibling group as a whole, except for drusen characteristics in the peripheral macula of male sibling pairs (weighted $x$ values) (Table 3 ).

For each attribute the difference was significant when analysed by $\chi^{2}$ (Table 4 ).

\section{Discussion}

Our findings, based on an objective analysis of the fundus photographs, show a consistently

A

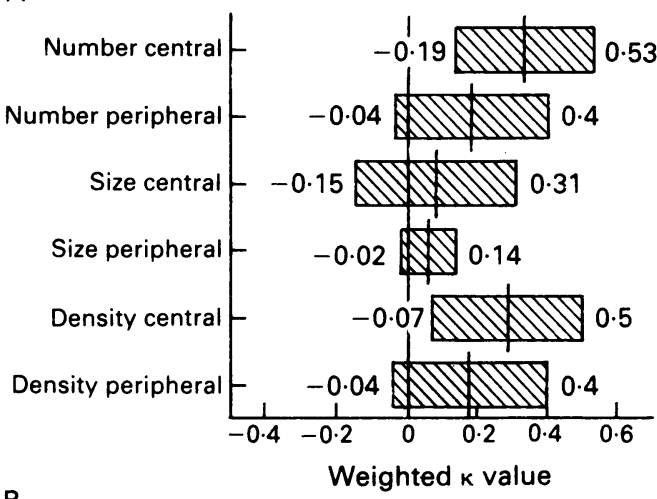

B

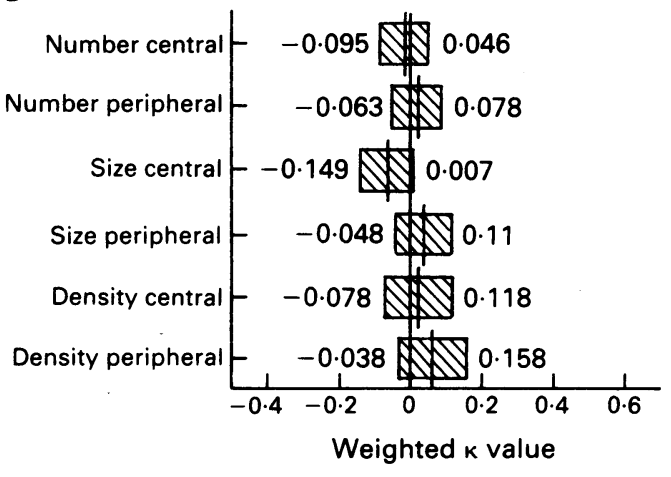

$95 \%$ Confidence interval

Weighted $\kappa$
Table 3 Weighted $x$ values in siblings of the same sex

\begin{tabular}{|c|c|c|c|c|}
\hline & \multicolumn{2}{|c|}{ Central } & \multicolumn{2}{|c|}{ Peripheral } \\
\hline & $x$ & $S E$ & $x$ & $S E$ \\
\hline \multicolumn{5}{|c|}{20 Female sibling pairs: } \\
\hline Number & $0 \cdot 44$ & $0 \cdot 17$ & 0.37 & $0 \cdot 18$ \\
\hline Density & $0 \cdot 24$ & $0 \cdot 18$ & $0 \cdot 14$ & $0 \cdot 17$ \\
\hline Size & $0 \cdot 20$ & $0 \cdot 14$ & 0.05 & 0.06 \\
\hline \multicolumn{5}{|c|}{10 Male sibling pairs: } \\
\hline Number & $0 \cdot 28$ & $0 \cdot 19$ & -0.05 & $0 \cdot 29$ \\
\hline Density & $0 \cdot 20$ & $0 \cdot 18$ & $-0 \cdot 38$ & $0 \cdot 20$ \\
\hline Size & 0.00 & 0.58 & 0.00 & 0.04 \\
\hline
\end{tabular}

Table 4 Frequency of differences in rating between siblings and spouses for each proband. Cells of less than 5 have been added to the neighbouring cell for statistical analysis

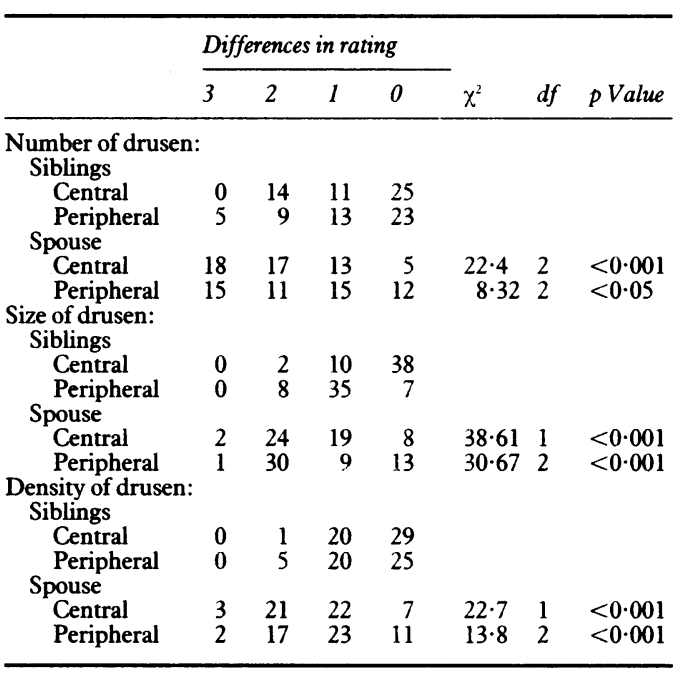

higher correlation of drusen characteristics between siblings than between spouses, which supports the concept that there are genetic influences in the pathogenesis of age-related changes at the level of Bruch's membrane. These results are consistent with conclusions drawn by previous authors. ${ }^{25} 27$

It could have been that the higher concordance between siblings than between spouses results from the presence of pairs of the same sex among siblings but not spouses if there were a difference in age-related changes between men and women. However, the fact that the concordance of sibling pairs of the same sex did not differ from the group as a whole denies this possibility. In addition, the difference between women and men in the prevalence of age-related maculopathy implied by several studies ${ }^{2627}$ is now in doubt. In a recent analysis of the Framingham eye study, Sperduto and Siegel ${ }^{35}$ redefined ARM by ophthalmoscopic appearance and removed visual acuity as a criterion of aging macular degeneration, since many of the elderly patients had concomitant cataracts. It was found that ARM was approximately equal in frequency between men and women of comparable age groups. This conclusion was also drawn by others who analysed the data from the National Health and Nutrition Examination Survey. ${ }^{36} 37$ In a large series of eyes with ARM examined histologically Green found a higher prevalence of drusen in men. ${ }^{14}$

If genetic influences are important, $x$ values expressing a low level of concordance should not be surprising given that siblings share genetic 
characteristics but do not have identical genetic make up as would be the case in identical twins, and it is likely that the predisposition is multifactorial rather being due to a single gene. Various genetically determined ocular characteristics such as hyperopia ${ }^{26} 2729$ or iris colour ${ }^{27}$ have been recognised as being associated with $A R M$, and it is likely that many other hereditable factors may play a role in modulating risk. The degree of concordance between siblings would depend on the number of genetic determinants shared by the subjects. The much larger standard errors seen in the $x$ values for the sibling pairs than for the spouse pairs would also be expected if there were genetic predisposition, since there would be wide variation in the shared genetic factors influencing the disorder.

In addition it is well established that the fundus changes in families with documented autosomal dominant disease associated with drusen may vary widely from small discrete to large confluent drusen in different members, and that the two forms may exist in the same eye..$^{23} 38$

The complete absence of concordance between spouses who have shared a common lifestyle for more than two decades suggests that environmental factors alone are unlikely to have a major impact on the genesis of the disease. However, they cannot be ruled out, particularly if they are important in early life since siblings share a similar early environment. It is also possible that the variation in lifestyles among the patients included in this study was insufficient for its influence to be manifest.

That the development of change in Bruch's membrane with age is influenced more by genetic than environmental factors in Western society is in accord with the view expressed by others. ${ }^{25} 2739-41$ We have not sought to identify which inherited factors may be important in the genesis of drusen to date but the data suggest that such a study may be fruitful. In addition we have not undertaken any correlation of visual loss and familial predisposition which would reflect the factors important to the reaction of the eye to deposits in Bruch's membrane in addition to those which determine the quantity and chemical composition of the deposits.

This study was supported by The Medical Research Council of the This study was supported by The Medical Resear

UK, London and The Wellcome Trust, London. la Recherche Scientifique, the Holderbank and the JanggenPoehn Stiftung.

1 Estimated statistics on blindness and visual problems. New York: National Society for Prevention of Blindness, 1966: 44.

$2 \mathrm{Kahn} \mathrm{HA,} \mathrm{Moorhead} \mathrm{HBV.} \mathrm{Statistics} \mathrm{on} \mathrm{blindness} \mathrm{in} \mathrm{the}$ reporting model areas 1969-70. United States Department of reporting model areas $1969-70$. United States Department of Health, Education and Welfare Publication No (NIH) 73427. 1973.

3 Leibowitz H, Krueger DE, Maunder LR, Milton RC, Kim MM, Kahn HA, et al. The Framingham eye study monograph. An ophthalmological and epidemiological study of cataract, glaucoma, diabetic retinopathy, macular degeneration and visual acuity in a general population of 2631 adults, 1973-75. Surv Ophthalmol 1980; 25 (suppl): 335-610.

4 Ghafour IM, Allan D, Foulds WS. Common causes of Ophthalmol 1983; 67: 209-13.
5 Bressler NM, Bressler SB, Fine SL. Age-related macular degeneration. Surv Ophthalmol 1988; 32: 375-413.

6 Feeney-Burns L, Gao CL, Tidwell M. Lysosomal enzyme cytochemistry of human RPE, Bruch's membrane and drusen. Invest Ophthalmol Vis Sci 1987; 28: 1138-47.

7 Feeney-Burns L, Ellersieck MR. Age-related changes in the ultrastructure of Bruch's membrane. Am $\mathcal{F}$ Ophthalmol 1985; 100: 686-97.

8 Burns RP, Feeney-Burns L. Clinico-morphological correlations of drusen and Bruch's membrane. Trans Am Ophthalmol Soc 1980; 78: 206-25.

9 Ishibashi T, Sorgente N, Patterson R, Ryan SJ. Pathogenesis of drusen in the primate. Invest Ophthalmol Vis Sci 1986; 27: of drusen

10 Reme C. Autophagy in visual cells and pigment epithelium Invest Ophthalmol 1977; 16: 807-14.

11 Young RW. Pathophysiology of age-related macular degeneration. Surv Ophthalmol 1987; 31: 291-306.

12 Hogan MJ, Alvarado J. Studies on the human macula. IV Aging changes in Bruch's membrane. Arch Ophthalmol 1967; 77: 410-20.

13 Sarks SH. Ageing and degeneration in the macular region. A clinico-pathological study. Br f Ophthalmol 1967; 60: 324 41.

14 Green WR, Key SN. Senile macular degeneration. A histopathological study. Trans Am Ophthalmol Soc 1977; 75: 180254.

15 Grindle CFJ, Marshall J. Aging changes in Bruch's membrane and their functional implications. Trans Ophthalmol Soc UK 1978; 98: 172-5.

16 Killingsworth MC. Age-related components of Bruch's membrane in the human eye. Graefes Arch Clin Exp Ophthalmol 1987; 225: 406-12.

17 Hutchinson J, Tay W. Symmetrical central choroido-retinal disease occurring in senile persons. Roy Lond Ophthalmic Hosp Rep 1875; 83: 275-85.

18 Holthouse EH, Batten RD. A case of superficial choroidoretinitis of peculiar form and doubtful causation. Trans Ophthalmol Soc UK 1897; 17: 62-3.

19 Doyne RW. Peculiar condition of choroiditis occurring in several members of the same family. Trans Ophthalmol Soc several members

20 Forni S, Babel J. Etude clinique et histologique de la malattia levantinese: affection appartenant au groupe des degenerescences hyalines du pole posterieur. Ophthalmologica 1962; 143: 313-22.

21 Pearce WG. Genetic aspects of Doyne's honeycomb degeneration of the retina. Ann Hum Genet 1967; 31: 173-9.

22 Pearce WG. Doyne's honeycomb retinal degeneration: clinical and genetic features. Br $\mathcal{O O p h t h a l m o l} 1968 ; 52: 73$.

23 Deutman AF, Janssen LMA. Dominantly inherited drusen of Bruch's membrane. Br f Ophthalmol 1970; 54: 373.

24 Franceschetti A, Francois J, Babel J. Les heredo-degerescences choroido-retiniennes. Paris: Masson, 1963.

25 Gass JDM. Drusen and disciform macular detachment and degeneration. Arch Ophthalmol 1973; 90: 206-17.

26 Hyman LG, Lilienfeld AM, Ferris FL, Fine SL. Senile macular degeneration: a case-control study. Am $\mathcal{f}$ Epidemiol 1983; 118: 213-27.

27 Delaney $W$, Oates $R$. Senile macular degeneration: a preliminary study. Ann Ophthalmol 1982; 14: 21-4.

28 Kahn HA, Leibowitz MM, Ganley JP, Kini MM, Colton T, Nickerson RS, et al. The Framingham eye study. II. Association of ophthalmic pathology with single variables previously measured in the Framingham heart study. $A m \mathcal{F}$ Epidemiol 1977; 106: 33-41.

29 Maltzman BA, Mulvihill MM, Greenbaum A. Senile macular degeneration and risk factors: a case-control study. Ann Ophthalmol 1979; 11: 1197-201.

30 Gregor Z, Bird AC, Chisholm IH. Senile disciform macular degeneration in the second eye. Brf Ophthalmol 1977; 61: degenerat

31 Chuang EL, Bird AC. The pathogenesis of tears of the pigment epithelium. Am F Ophthalmol 1988; 105: 285-93.

32 Barondes MJ, Pauleikhoff D, Chisholm IM, Bird AC Bilaterality of drusen. Br 7 Ophthalmol 1990; 74: 180-2.

33 Pauleikhoff D, Barondes MJ, Minassian D, Chisholm IH, Bird AC. Drusen as risk factors in age-related macular disease. Am F Ophthalmol 1990; 109: 38-43.

34 Fleiss JL. Statistical methods for rates and proportions. 2nd ed. New York: Wiley, 1981.

35 Sperduto RD, Siegel $D$. Senile lens and senile macular changes in a population-based sample. Am 7 Ophthalmol 1980; 90: 86-91.

36 Martinez GS, Campbell A, Reinken J, Allen BC. Prevalence of ocular disease in a population study of subjects 65 years old ocular disease in a population study of subjects
and older. Am $\mathcal{F}$ Ophthalmol 1982; 94 : 181-9.

37 Klein B, Klein R. Cataracts and macular degeneration in older Americans. Arch Ophthalmol 1982; 100: 571-3.

38 Francois J. L'heredite des degenerescences maculaires. Ophthalmologica 1974; 168: 417-45.

39 Klein $B$. The heredodegenerations of the macular lutea: diagnostic and differential diagnostic considerations and a histopathologic report. Am $\mathcal{F}$ Ophthalmol 1950; 33: 371-9.

40 Elwyn $H$. Heredodegenerations and heredoconstitutional defects of the retina. Arch Ophthalmol 1955; 53:619-33.

41 Krill B, Deutman AF. Dominant macular degenerations - the cone dystrophies. Am f Ophthalmol 1972; 73: 352-69. 